\title{
The Qualitative Research Interview: Fashioning Respondent Affinity
}

\author{
Tony Dundon \\ J.E Cairnes School of Business and Economics \\ National University of Ireland, Galway \\ Galway, Ireland \\ Tel: 353-9149-2356_E-mail: tony.dundon@nuigalway.ie \\ Paul Ryan \\ J.E Cairnes School of Business and Economics \\ National University of Ireland, Galway \\ Galway, Ireland \\ Tel: 353-9149-2020Ｅ-mail: paul.j.ryan@nuigalway.ie
}

\begin{abstract}
This article reports on the stages of developing respondent rapport and affinity during the qualitative research interview. It advances knowledge in terms of respondent dialogue in the collection of data and its subsequent analysis. The article assesses how the researchers overcame a cautious and suspicious reception from interview respondents. The article details how the process of rapport can be beneficial to the collection of quality data.
\end{abstract}

Keywords: Interviews, Case study method, Respondent reluctance, Overcoming bias 


\section{Introduction}

Interviews, no matter how well designed and planned, often fail to elicit meaningful data. Even the most efficient researcher can encounter unforeseen problems (Kvale, 1996). These are especially evident for interviews concerned with management and business-related topics, for a variety of reasons. The most simple is that respondents pull-out and cancel at the last minute due to time pressures or unplanned work commitments. A more difficult problem, however, arises when a respondent agrees to an interview but is reluctant to divulge the level and detail of information required. This can be as a result of a lack of interest in the research agenda on the part of the interviewee or a reluctance to engage in the research topic. The consequences can be highly problematic and even derail the entire research project.

In this paper we show how an interview had to be turned-around from one of almost complete disengagement by interviewees to one characterised by a solid level of engagement. This involved the researchers adjusting to circumstances, providing prompts and exploiting opportunities to develop rapport with respondents. Why interviewees withhold information or become reluctant to disseminate all the relevant facts about an issue or topic are varied, ranging from inadequate knowledge of the subject under investigation, to concerns over issues of confidentiality or time pressures (Lavin and Maynard, 2001). Of particular relevance for this paper, there can also be an initial disinterest in the research 'agenda'. This difficulty can be made worse by a lack of rapport between the respondent and researcher, leading to a general disengagement with the interview process. Some of these problems simply cannot be overcome. No matter how much rapport and engagement is nurtured between the researcher and interviewee, this cannot eliminate a lack of knowledge surrounding the topic under inquiry. Other obstacles to information retrieval can be managed to some extent (Sekaran, 2003). For instance, confidentiality can be assured and time management expectations can be clarified. Interviews can be re-scheduled to minimise disruption and garner the optimum information to minimise inconvenience to the interviewee. Finally, general disinterest or disengagement can be overcome through the development of a rapport with the interviewee, and tackling this particular issue is the basis of this paper. From the outset, however, it ought to be recognised that the interviewer of a 'qualitative' data collection process can be against the clock. The objective is commonly to derive as much information as required with the minimum of disruption and in the shortest period of time. Therefore, the dilemma is a circular 'chicken-and-egg' scenario. On the one hand, without rapport the interviewee may be disengaged from the process. Yet on the other hand, developing rapport utilises scarce time available for the gathering of required information.

The remainder of this paper narrates the story of how a two-person research team moved from a situation of almost complete disengagement to one of close rapport, empathy and understanding between interviewer and interviewee. In the first section we briefly outline the research project. In the second section a backdrop to the case study organisation and who the respondents are is given. The case study, Waterford Wedgewood Crystal, is based in the Republic of Ireland. Employment relations at Waterford Crystal have at times been characterised as conflictual with a highly-charged union-management relationship. The interviewees were the on-site union officials of a well-known trade union, the Amalgamated 
Transport and General Workers Union (AT\&GWU). They participated in the interview at the behest of management, not the researchers. Thus the initial interaction was through management rather than being initiated directly by the researchers. From the outset the interviewees viewed the project with suspicion, having never had any prior contact with the researchers. This context is important, demonstrates the significance of contextual-dependent information surrounding an interview process. The third section narrates the interview itself. The final section of the paper outlines some general guidelines to help develop respondent rapport during an interview-based research project.

The story told in this paper illustrates how the development of rapport is best viewed as a staged process. Significantly, it describes how these stages have to be subtly moved through at a quite rapid pace whilst simultaneously ensuring confidence is developed rather than lost. The paper shows the extent to which interviewee disclosure and data collection can be enhanced after rapport is secured.

\section{The Research Project: Its Methodology and the Theory of Respondent Rapport and Affinity}

The interview story is based in a single case study drawn from a much larger research project that included 15 organisations in total (for details see Dundon et al, 2006). The particular research project was more policy-orientated than theoretical: it was multi-disciplinary and involved interviewing multiple role holders at different levels to explore complex social processes at the enterprise level. The research was concerned with the factors influencing change management as a result of European employment regulations (e.g. the European Directive for Employee Information and Consultation). Thus the questions asked and the methodology used was determined by a changing regulatory environment for employee voice that was occurring in Ireland (and the UK) at the time.

The approach is best described as 'social action' research, which "attempts to come to grips with the meanings of a situation [for] those involved in it” (Silverman, 1970:224). There is no universal definition of respondent rapport or affinity. Some authors view rapport as 'frank and open discussion' (Goudy and Potter, 1975), while others see it as a degree of acceptance or cooperation on the part of the interviewee to a research project (Blohm, 2007). Lavin and Maynard (2001) argue that the concept of rapport is difficult to measure, and consequently favors a more global interpretation of the attitudes and behaviors displayed during the interviewer-respondent relationship. Notwithstanding definitional ambiguities, nurturing and developing affinity with interviewees falls under the rubric of rapport-building skills (Kvale, 1996; Sekaran, 2003). This is recognised for both standardized and less structured interviewing (Fowler and Mangione, 1990).

We were interested in using the interview process to explore at a deeper level the meanings of employee voice for union officials. A case study strategy was employed so as to allow role holders the opportunity to explain and reflect on the detail of information and consultation mechanisms in their own words. Various research instruments were utilized in this regard: semi-structured interviews with different actors, company documentation, and in some of the cases an employee attitude survey. What is reported here is one set interviews with a single 
respondent group from one organisation: the union conveners of the AT\&GWU based at Waterford Crystal. The approach was qualitative in nature and the interview schedule was designed around several conceptual and analytical themes derived from existing theory and research about the topic of regulating for employee voice. It is important to note that this case study strategy did not search for broad generalizations across a defined population or sample, but rather to understand particular situations as encountered by the respondents themselves. With this approach the researcher is then allowed to place the data in a wider context of explicit and implicit influences surrounding the phenomena under investigation. For this reason, a contextual backdrop to the case study is important.

\section{The Case Study Context: Waterford Wedgewood Crystal}

In finding a case study that is 'suitable', a researcher is often dependent on the combination of accident, fortune and guesswork. This is because there are no clear guidelines for what makes a suitable or robust case. Indeed, it has been argued elsewhere that the meanings and interpretations of complex social relationships can never be fully understood until the research has commenced at the organisational level (Gouldner, 1955). The case study reported here was deemed suitable for the project because it had experienced considerable change during its long and varied history. There also existed strong and well-established union-management structures for employee participation and social partnership.

Waterford Wedgewood began its operations as Waterford Crystal in 1783 to manufacture hand-crafted glassware. Waterford Wedgwood plc was established in 1986 with the merger of Waterford Crystal and Wedgwood. With a combined history of over 600 years of heritage, tradition and craftsmanship, today Waterford Wedgwood is among the world's leading luxury goods manufacturers with global brands that include Waterford Crystal, Wedgwood, W C Designs, Rosenthal and All-Clad. At present the company is represented in 80 countries worldwide and has a combined workforce of over 9000 . The company and its workforce have experienced significant change and re-organisation. It faced severe economic recession during the late 1980s and became known for its lack of technological innovation and combative industrial relations. In response to market pressures Waterford Wedgewood consolidated its position by disposing of unrelated companies. Many of the changes were extremely painful for both workers and the company. Redundancies, wage freezes and wage cuts and changes to work practices were all introduced. Many of these changes culminated in a bitter and protracted 14 week strike in 1990, during which time the on-site union convenor (e.g. the principal interviewee for this research) was sacked by management for public speeches that intimated threats to the company owner, Sir Anthony O'Reilly. After a public apology by the union convenor on a local radio programme, the dismissal was revoked as part of the return to work agreement.

The AT\&GWU has a tradition as a militant rather than moderate union. It is perhaps the only union in Ireland that publicly opposes the government's partnership approach to industrial relations, believing vehemently that the concept of partnership is a euphemism for managerial control and the exercise of power over workers. The union is also suspicious of employment regulations that emanate from a supra-national body such as the European Commission, 
believing instead in free collective bargaining rather than what it would term a form of collusion with state institutions that do no more than support and prop-up a capitalist system for employer-dominated interests.

Either in spite or because of its militant values, the union has negotiated several collective-based structures for worker participation at the case study plant. There is a closed shop union agreement which ensures $100 \%$ union membership as a condition of employment for production workers. Agreements provide for three elected union representatives (conveners) to be released from their daily work tasks to carry out union activities. In addition there are numerous departmental-level shop stewards who meet with management and conveners on a regular basis. For example, there is a Joint Negotiating Committee (JNC) in which the three conveners meet with company directors on a weekly basis. Senior plant management also consult with union representatives over a wide range of issues at a weekly Monitoring Steering Committee, including full disclosure of commercially sensitive information. At lower levels there are several Task Groups (TGs) comprising union and management representatives that meet on a regular basis and consider information such as production schedules, shipping quantities, quality issues and production costs. Further participatory structures include Sectional Consultative Committees (SCCs) between shop stewards and supervisors of particular occupational and functional categories, such as glass blowers, cutters or packers. In short, there already exist at the plant extensive collective-based structures for employee information and consultation via the elected representatives of the workforce. These voice channels have been used to facilitate a programme of change and radical restructuring. At times these changes were unpalatable to the union and workforce with episodes of resistance and non-agreement.

\section{The Interview Narrative}

As with many research projects, obtaining agreement and permission from management is crucial to gain access. It was management that agreed to participate in the research study and insisted - probably in the spirit of cooperation and inclusion - on union involvement. Thus it was the company management who introduced us to a disgruntled, stony-faced and time-pressed duo of union convenors on a bleak mid-November morning. Worse still, the interview commenced in what was clearly an alien environment: the HR Manager's plush office. The tone that was set was immediate and self-evident: we, the researchers, were 'identified' with management rather than as independent researchers.

\subsection{Stage I: Opening the Interview}

As soon as the HR Manager departed, the researchers were left in little doubt that the interviewees felt that these two clueless academics had been imposed on them by management. A third party who was loitering with no obvious or apparent intent in the office had not been asked to remove himself while the interview took place. This signalled to the researchers that the interview about to commence would neither be of long duration nor provide the narrative, anecdotes and illustrations required to get to the grips with complex social processes surrounding union-management consultation. As noted above, there was a growing sense that the researchers were somehow complicit with management in the purpose 
of the interview. However, there was also a sense that they (the interviewees) were unsure as to what it was we (the researchers) were complicit in. Nevertheless, this was evidently neither the time nor the place to find out. We briefly introduced ourselves and the project objectives. At this point it is worth noting that prior to the case study visit publically available information had been collected on the AT\&GWU (and their role at Waterford Wedgwood). Thus the researchers were to some degree familiar with the union, its broad policy objectives and the company's position concerning things like social partnership and its link to employee voice and union participation.

As the interview began it became evident that because one of the researchers is a native of Liverpool, his scouse ${ }^{1}$ accent elicited a mild sense of curiosity amongst the union convenors: "what brought you from Liverpool to Ireland, what do you do at the university", and so on. The context was that the interviewees were commenting on the fact that the union's general secretary, based in London, was also a 'scouser'. This signalled an important phase in the first stage of the interview process as respondents sought to elicit information and some further understanding as to our motives in conducting the research. Notwithstanding this, the overriding sense was one of almost outright hostility. At best, we were a major inconvenience and nuisance who had distracted the union convenors from their more important work. Despite the researchers' attempt to progress to the more substantive parts of the interview schedule, it was apparent at this point that the respondents were just 'going through the motions', of complying with managements' request to partake in the research. Questions and subsequent probes designed to facilitate open-ended responses were met with succinct affirmations or negations. At one level the respondents were respectful of our needs to have answers. Yet at a deeper level, the information given provided neither insight nor the elaborated extrapolations about union-management consultation that we sought.

\subsection{Stage II: Switching Direction}

The short and succinct respondent answers to our questioning indicated the need for some alternative direction for the interview. The diversionary tactic deployed can be illustrated by the metaphor of a typical security guard's role on the door of a night club (e.g. a 'bouncer'). A tactic often employed by bouncers when confronted with over-inebriated and aggressive would-be entrants is known as the 'switch'. Rather than face-up to the disgruntled customer and argue about access to the club, the 'switch' creates a diversionary blocker whereby one bouncer tactfully steps aside and permits another to intervene. This new and more 'reasonable' bouncer explains quite politely the reasons that entry is not possible at this moment in time. Whilst still unhappy, the over-inebriated would-be entrant has their attention diverted away from the initial blocker, the bouncer refusing admission, to someone who seems apologetic and less 'guilty' of the refusal to admit.

At this stage of the interview we were in need of such a switch. The mechanism employed was an intervention to request a drink. The intervention was made by the second interviewer, a non-Liverpudlian Irishman, asking "in the absence of decent Guinness around here, is there any water". The Liverpudlian stepped-aside to allow the Irish researcher to initiate the switch.

\footnotetext{
1 'Scouse' is a person from Liverpool with a distinctive dialect unique to Liverpool
} 
Significantly, the qualifier of mentioning Guinness in the same sentence as water was not accidental. It generated a further detail to the subsequent conversation around what is and what is not 'decent' Guinness. As water was being dispensed from the HR Manager's own personal dispenser in his office, the Liverpudlian invoked a further switch, suggesting that "such important matters as 'decent' Guinness might be best resolved over a coffee, not water". The coffee option was agreeable. More importantly, this necessitated a trip to the canteen, and as such a much bigger 'switch' than was hoped for ensued.

\subsection{Stage III: Searching for a Common Ground}

Although still in its infancy, the switch offered a temporary reprieve from the respondents' reluctance to furnish the detailed level of information we sought. Such a reprieve signalled another stage on the journey to establish rapport and build a degree of empathy with the interviewees. More importantly, by moving from the HR Manager's office to the factory canteen, a more fluid conversation was established in a less intimidating environment. Conscious of the significance of the switch, we realised time was crucial to be able to develop a level of rapport that would be more satisfactory to the research objectives. The transformation from a reluctant to more supportive atmosphere needed to be rapid and decisive. As the union convenors walked to the coffee dock, we, the researchers, split-up. The Liverpudlian chatted with the more senior union convenor who seemed curious about the project and the potential implications of the proposed EU Directive on employee voice. The Irish researcher spoke with the second union official, who was known to be a strong critic of the Irish government's partnership approach. From prior research about the union it was discovered that he is the more militant ideologue: a Marxist. The Irish researcher decided to turn the conversation away from the project and its relevance to union-management power relations and to talk about something else. This involves and element of risk. The switch described above changed the location and altered the direction of conversation between interviewer and interviewee. However, identifying an alternative and more general, non-threatening topic to build rapport is always risky. The topic can be anything but the respondent has to be able to engage in a genuine way with its substance. This is a search for a universal subject with a common language. The Irishman's knowledge of recent Gaelic sporting events that had occurred the day before the interview offered the common ground to open-up a rapport in new and more engaging ways.

The local sporting team had lost an important game to its neighbours, and it was known that supporters of both teams worked side-by-side in the plant. The conversation opened with a question: "So what went wrong yesterday?". The tenor of the question meant that no further elaboration was required. "Not up to it", replied the Marxist union official. "It must be tough losing to them, replied the Irish researcher. "Yes. It's bad in here today. It's been going on all morning. I'm bloody sick of all the slagging”, said the union convenor. The Irish interviewer found an opening to show empathy: "Ye had your chances though. The rest of us were for ye. They're an arrogant shower", implying the neighbouring team won only after a hard and proud display by the union convenor's preferred team. The conversation paved the way for further non-threatening dialogue: "So where are you from?", asked the union convenor of the Irish researcher. As he explained his background, where he was born and his father's 
long-held distaste of the team that had won and caused the militant such discomfort, the first semblance of a bond was beginning to emerge.

\subsection{Stage IV: Establishing Empathy}

During coffee the conversation stayed off the topic of the research and moved from Gaelic football, to the weather and what life was like in Galway (the city in which the researchers' university is based). The union convenors were still curious about how a Liverpudlian came to work in an Irish university. The conversation eventually turned to how the Liverpudlian had once been a union steward and had previous dealings with union officials of several unions in Britain, including the general secretary of the convenor's union, the AT\&GWU. The scouse researcher's personal journey from union rep to university lecturer was related. Mutual acquaintances in the labour movement and linkages to others on the political left were exchanged. Existent sympathies with worker concerns and empathy for union organising were swiftly and firmly established.

The nature of the conversation was much more natural and fluid; signalling another important stage in the process of rapport building with reluctant respondents. The substance and details of the conversations were neither intentional nor planned. The subject matter was something that evolved in response to the dynamics of the situation as it unfolded. However, what was conscious was the tactic of a switch, and in so doing a readiness on the part of the researchers to develop new lines of respondent engagement. Once the less threatening and more common ground for dialogue was found, a degree of empathy between interviewee and interviewer was established. From that moment we (the interviewers) were no longer perceived as being identified with management or on the side of the company. We had shifted from an 'outsider' to 'insider' status for the purpose of the interview. At the instigation of the union respondents, we returned to the substantive topic of the research. The difference, however, is we resumed not in the canteen over coffee or the HR Manager's office with its personal water dispenser: we returned to the interview in the union's own office elsewhere in the plant. We had now established a sufficient degree of empathy and trust that the interview could proceed along the lines as originally hoped.

\subsection{Stage V: The Dynamic of Respondent Trust}

The interview recommenced on a much more engaged, interactive plane. Gone were the curt, uninformative answers. In their place were fully fleshed out narratives, relevant and often amusing anecdotes, elaborations of the union convenors' concerns for the company's future and rich illustrations of the affection for their locality. Their disillusionment with, as they saw it, management inadequacies and the detail of how 'information and consultation' worked in practice sprung forth in abundance. One particular revelation was the union's acute sensitivity to the market environment faced by the company and their role in calling management to account. The non-militant union convenor explained:

"We don't want to be the financial controller of the company [and] management can't be held responsible for economic downturns or war. But if competitors are up then we have the data so management is held responsible”. 
Almost immediately, the more militant union rep added:

"If people give out that a strike or disagreements will shut the place down, then shut it down. You have to stop somewhere, they can't take it all”

Without an appreciation of the organisational context and the way the interview unfolded, the above could be misinterpreted as a signal of tension or disagreement between the two union conveners. Nothing could be farther from the truth. Both were in broad agreement with one another and both further elaborated on the need for the company to be competitive and responsive to global market pressures. Yet there was a clear boundary to which the union and the workforce could cooperate and support managerial decisions that would ultimately have a detrimental impact on workers. The interview was uncovering the social dynamics associated with power relations between capital and labour.

Equally important data was conveyed during the interview that painted an entirely different picture of the respondents themselves: certainly a more genuine character emerged than would have been gleaned from the opening stages of the interview. The conveners' understanding of, and sensitivity to, the commercial and global market pressures faced by Waterford Crystal were impressive and articulate. Alongside this they had an unequivocal passion for their craft, their union members, a respect for management and a proud loyalty to the brand of Waterford Crystal. A short example illustrates the significance of the data and the importance of its context. The Marxist convenor talked about the craft of glass-blowing and the making of well-known commissioned crystal-ware; for example, the tennis masters series and worldwide golf tournaments. The militant union rep revealed a loyalty to his craft and a commitment to his company unsurpassed elsewhere in the 15 case studies associated with the research project. Waterford Crystal was commissioned to design and make a gigantic crystal ball, which was used to mark the beginning of the new millennium in New York's Times Square. The militant union convenor recalled how he and his family continued with their new year's eve celebrations until 5am the next morning ${ }^{2}$. The reason was to view the televised pictures of the millennium celebrations as they occurred in New York; their fingers-crossed that all went well with the priceless crystal ball crafted by his members. He proudly explained that he became quite emotional at viewing what the workers of Waterford Crystal had made and its public display on a world stage.

The example serves to illustrate how the direction of an interview can affect the depth of information revealed in a short space of time. The precise detail about the New York millennium ball was to some extent peripheral to the questions designed for the research project. However, the level of rapport that had been established meant there was a new dynamic to the interview: there was a level of trust between interviewer and interviewee which uncovered important nuances and twists and turns in the story of information retrieval and data collection.

\subsection{Stage VI: Post-Interview Rapport}

\footnotetext{
${ }^{2}$ Ireland is 5 hours ahead of New York
} 
The most surprising twist in the narrative occurred as the interview came to a close. We initially thought the interview would be very short with little more than blunt and unelaborated answers, however after the 'switch' (see Stage II above), the interview lasted for about 4 hours. It was enjoyable, highly informative and peppered with fascinating anecdotes and stories about the company, the union and its workforce. We were extremely pleased with the depth of information collected. However, and unbeknown to us at this time, data collection didn't end as the formal interview closed. As we were winding-up the interview and thanking the union respondents for their time, we were offered an unrequested tour of the plant by the two union convenors. This is where the most surprising revelation occurred, and the story takes a slight diversion while we were escorted around the factory.

Waterford Crystal is a long-established business that has become an official tourist attraction in Ireland. The union convenors took us across the factory and we joined the mass of (mostly American) holidaymakers who were midway through an official tour of the facility. The company's history and its products were being explained, with photos and replicas of the more famous items and sporting trophies made by Waterford Crystal. Upon arrival the tour guides (company employees) gave a small nod to the union convenors. Our presence was acknowledged but nothing was said: we were in safe and trusted hands and the official guides left us and the union reps to our devises as we mingled alongside paying tourists.

The next stage of the tour included an observation deck overlooking a team of about eight workers who were blowing glass and crafting crystal wares. The union convenors, being well-known in the company, were allowed to usher us towards the front as the guide was explaining the jobs being performed and products getting made. These workers were evidently highly skilled and worked in hot and sweaty conditions. The job involved a delicate task with smouldering (melted) glass from a furnace, balanced on the end of a long tube. With intricate hand and mouth coordination, the workers would blow an individual item of glass, similar in shape and size to a large round fish bowl. This involved hot melting glass being blown and twisted into shape. When the glass is of a particular shape and size in the blowing process, the worker would dip it into a coolant, from which was then crafted a piece of crystal ware by other workers in an adjoining team. The scene conjured-up images of how the hand-crafted millennium ball that descended on Time Square in New York was made.

In ushering us towards the front we had a privileged position to view the production process, although that was not entirely the motive of our hosts, the union convenors. They facilitated this premium viewing position because they also knew what was coming next in the company's official tour. As the company guide called for a volunteer, the Irish researcher swiftly and tactically stepped back, leaving for a few seconds the Liverpudlian out in front with the mass of tourists. With a nod and wink from the union convenor to the company tour guide, the scouser was seconded to perform the same glass blowing tasks that had just been observed. With the melting glass in flames, loaded on the long tube and now in full view of encouraging American tourists, there was little point in any objection. The best that could be hoped for was the Liverpudlian might be able to display some semblance of competence alongside the artisan instructing him on how to blow the glass. He failed. The skilled craft worker, with what seemed to be minimal effort, demonstrated how to blow the glass while 
simultaneously spinning the tube to ensure maximum leverage. Within a few seconds he produced a crystal bowl that was perfectly curved and approximate 15 inches in diameter. He dipped it in the coolant and cut it from the tube ready for the next stage. In contrast, the Liverpudlian blew with all the wind he could muster, expunging his lung capacity several times over, and only managed to produce a glass bubble the size of a thumb nail. Instead of skilfully dipping the red hot flame of glass into the coolant, it fell to the ground with a tiny splat. Nonetheless, the Americans cheered.

As the company's tour guides gathered everyone and moved to another part of the factory to continue with the Waterford Crystal tour, we were taken through an exit to the side. It was explained that we were about to enter a part of the plant that is 'out of sight' from the official tour. Amazingly, here was a scene far removed from the hand-craft production techniques we had only minutes before been witnessing and trying to partake in. There were a number of assembly lines which were spewing out mass produced crystal pieces that had been designed on computers. The image and brand of hand-made crystal was shown to be somewhat of an illusion: it was exclusive to commissioned pieces such as those for major sporting trophies. For the bulk of products, the only human involvement in the process were the hands of packaging workers that removed the finished pieces from the conveyor belt and carefully placed them in boxes for shipping.

The implications of the failed glass-blowing attempt and the sight of semi-hidden assembly lines were far-reaching, and beyond the remit of this paper. Suffice to say that we now believed we had obtained full disclosure; over-and-above what could have been hoped for or expected. Because the Liverpudlian was willing to 'have a go' at performing a craft without the requisite skill and competence, the respondents were further engaged. At the same time, because the Irish researcher collaborated with the union convenors that helped engineer the scouser's humiliation, a deeper and more trusting 'banter' was to some degree now embedded amongst researchers and interviewees. Whether this degree of engagement helped facilitate the subsequent observation of mass assembly lines or not, we are unsure. The revelation of mass production may have already been part of the union reps tour schedule. In any event, the turnaround from complete disengagement at the beginning of the interview to information retrieval was complete. On top of all that, we left with an unexpected gift-wrapped piece of crystal, courtesy of the union convenors, which remain to this day displayed in the researchers' offices.

\section{Conclusion: Fashioning Respondent Affinity}

We do not claim that the interview story told here is typical or common. In fact, the initial level of suspicion amongst the interviewees is itself an unusual situation. Most respondents of qualitative and interview-based research usually have some prior knowledge and understanding about the topic under investigation, and what is expected of them. Nonetheless, there are important lessons from the experience that show how rapport and affinity together with an appreciation of the changing dynamics of interview research, can lead to extensive information discourse. In summary, these lessons include:

- $\quad$ Establish your independence and credentials in the research process from the outset. 
- $\quad$ Select an interview venue where interviewees feel comfortable to communicate

- $\quad$ Don't rush into the interview schedule.

- Be sensitive to non-agenda opportunities to expand interaction to develop dialogue between interviewee and researcher.

- $\quad$ Be prepared. Know as much as possible about the interviewee, the organisation and any pertinent issues.

- Enjoy the discussion. Be open to anecdotes and illustrations that add longevity to the interview.

\section{References}

Blohm, M. (2007). The influence of interviewers' contact behavior on the contact and cooperation rate in face-to-face household surveys. International Journal of Public Opinion Research, 19 (1), 97-111.

Dundon, T., Curran, D., Maloney M. \& P. Ryan (2006). Conceptualising the dynamics of employee voice: evidence from the Republic of Ireland. Industrial Relations Journal, Vol 37 (5), 492-512.

Fowler, F. \& Mangione, T. (1990). Standardized Survey Interviewing: Minimising Interviewer Related Error, New York: Sage.

Gouldner, A. (1955). Wildcat Strikes. London: Routledge \& Kegan Paul.

Goudy, W. J. \& Potter, H. R. (1975). Interview Rapport: Demise of a Concept. Public Opinion Quarterly, 39 (4), 529-43

Kvale, S. (1996). Interviews: an introduction to qualitative research interviewing. London: Sage.

Lavin, D \& Maynard, D. (2001). Standardization vs. Rapport: Respondent Laughter and Interviewer Reaction during Telephone Surveys. American Sociological Review, 66 (3), 453-479

Sekaran, U. (2003). Research Methods for Business: A skill-building approach. New York: Chichester.

Silverman, D. (1970). The Theory of Organisations. London: Heinemann. 